\title{
A study of evaluation of unhealthy cervix by various diagnostic modalities
}

\author{
Ami M. Gohil, Sanjay Ponde*, Poorvi Agrawal, Himadri Bal
}

\begin{abstract}
Department of Obstetrics and Gynecology, Dr. D. Y. Patil Medical College, Dr. D. Y. Patil Vidyapeeth, Pimpri, Pune,
\end{abstract} Maharashtra, India

Received: 16 August 2019

Revised: 27 November 2019

Accepted: 07 December 2019

\author{
*Correspondence: \\ Dr. Sanjay Ponde, \\ E-mail: drsrponde@yahoo.com
}

Copyright: () the author(s), publisher and licensee Medip Academy. This is an open-access article distributed under the terms of the Creative Commons Attribution Non-Commercial License, which permits unrestricted non-commercial use, distribution, and reproduction in any medium, provided the original work is properly cited.

\begin{abstract}
Background: This study was carried out to evaluate cases of unhealthy cervix by using Pap (Papanicolaou) smear, colposcopy and cervical biopsy and to arrive at a definitive diagnosis. It correlated the findings of Pap smear, colposcopy and histopathology. It is important to strictly implement the screening program and spread awareness of the disease symptoms and its management to reduce the overall incidence of morbidity and mortality reported due to cervical cancer.

Methods: A total 120 patients satisfying the inclusion/exclusion criteria were recruited for the study and informed consent was taken from all the participants. Pap smear was taken for all the cases. Then cases were subjected to colposcopy followed by biopsy. All the findings were correlated and analyzed. The findings of Pap smear and colposcopy were correlated with the gold standard of histopathology.

Results: The sensitivity and specificity of Pap smear and colposcopy with respect to cervical biopsy were $53.1 \%$ and $98.7 \%, 87.87 \%$ and $72.72 \%$ respectively. Colposcopy had higher sensitivity and lower specificity than Pap smear for screening of cancer cervix.

Conclusions: Cervical cancer is one of the preventable and highly curable conditions when diagnosed in the precancerous stage. The incidence of deaths resulting from cervical cancer can be brought down with adequate cervical cancer screening. Colposcopy and colposcopy directed biopsy should be done along with Pap smear in screening for early detection of cervical cancer since the accuracy of detection of cervical abnormalities is higher when these two methods are used complementarily.
\end{abstract}

Keywords: Cervical biopsy, Cervical cancer screening, Colposcopy, Pap smear

\section{INTRODUCTION}

Dr. Ranjit Sen said, "Cancer is the most arrogant, independent, uncontrolled, highly destructive and proliferative, tissue invasive, hardly inevitable, renegade, apparently immortal population of body's own cells with the potential to metastasize and pollute the system with fatal terminal". ${ }^{1}$ Cervical cancer is one of the most common female reproductive system malignancies in the developing countries where organized cancer screening is non-existent.

Although worldwide cervical cancer rates have decreased dramatically with the increase in screening efforts, incidence and prevalence in developing countries remains high due to lack of screening programs, with approximately $80 \%$ of all cervical cancer deaths occurring in the developing world. ${ }^{2}$ 
Awareness among women and the Pap (Papanicolaou) test has made possible the early detection of this cancer. Pap smear and Colposcopy are the cornerstones for the screening of cancer cervix, though the specificity and sensitivity of each is different.

The Pap test is a procedure used to make a smear of exfoliating cells from the cervix on a slide, stain it and view it under the microscope to detect cancer and precancerous lesions. The Pap technique nonetheless is far from perfect and carries a $10-70 \%$ false negative rate due to collection and processing errors necessitating that the test be performed annually for optimal performance. ${ }^{3}$

A positive pap test becomes the indication for another procedure known as colposcopy. Colposcopy is an integral part of the management of women presenting with abnormal cervical cytology and those with lesions in the lower genital tract indicative of intraepithelial neoplastic disease. Colposcopy has established its place in the screening of cervical cancers as time went by. Colposcopy as a subjective modality has a sensitivity for the detection of intraepithelial disease in the range of 60 $75 \%$. When employed with exfoliative cytology, this sensitivity can be increased to $>90 \% .^{4}$

Unhealthy cervix is a group of cervical lesions which include chronic cervicitis including endocervicitis, cervical erosions, lacerations, and leucoplakia. These lesions can harbor premalignant lesions even when Pap smear is negative. ${ }^{5}$

We decided to compare and correlate the findings of Pap smear and colposcopy with the gold standard of histopathology for evaluation of cases of unhealthy cervix.

\section{METHODS}

A prospective observational study was conducted on patients attending gynecology OPD of a tertiary care teaching hospital between April 2016 and March 2018. The sequence has been mentioned in the flowchart below (Figure 1). Written informed consent was taken from all the participants before inclusion into the study. A thorough history including detailed personal and past medical history was taken, and then general and systemic examination was carried out. 120 patients coming with complaints of discharge per vagina and/or abnormal uterine bleeding along with clinical features of chronic cervicitis, cervical erosions, lacerations or leukoplakia were selected for the study. Women with growth over the cervix strongly suggestive of malignancy; women on hormonal therapy; pregnant and puerperal women; women with bleeding at the time of examination; and women with unsatisfactory colposcopy were excluded.

For Pap test, 2 cervical smears per patient were prepared using the Ayer's spatula and cytobrush. The smears were fixed by immersion in a Koplik jar, containing 95\% ethyl alcohol, for 20 minutes. The slides were then sent to the cytopathology laboratory for reporting. The reporting was done according to the Bethesda system. The patient was asked to follow up with the Pap report. On the follow up visit she was subjected to colposcopy followed by biopsy after taking due consent.

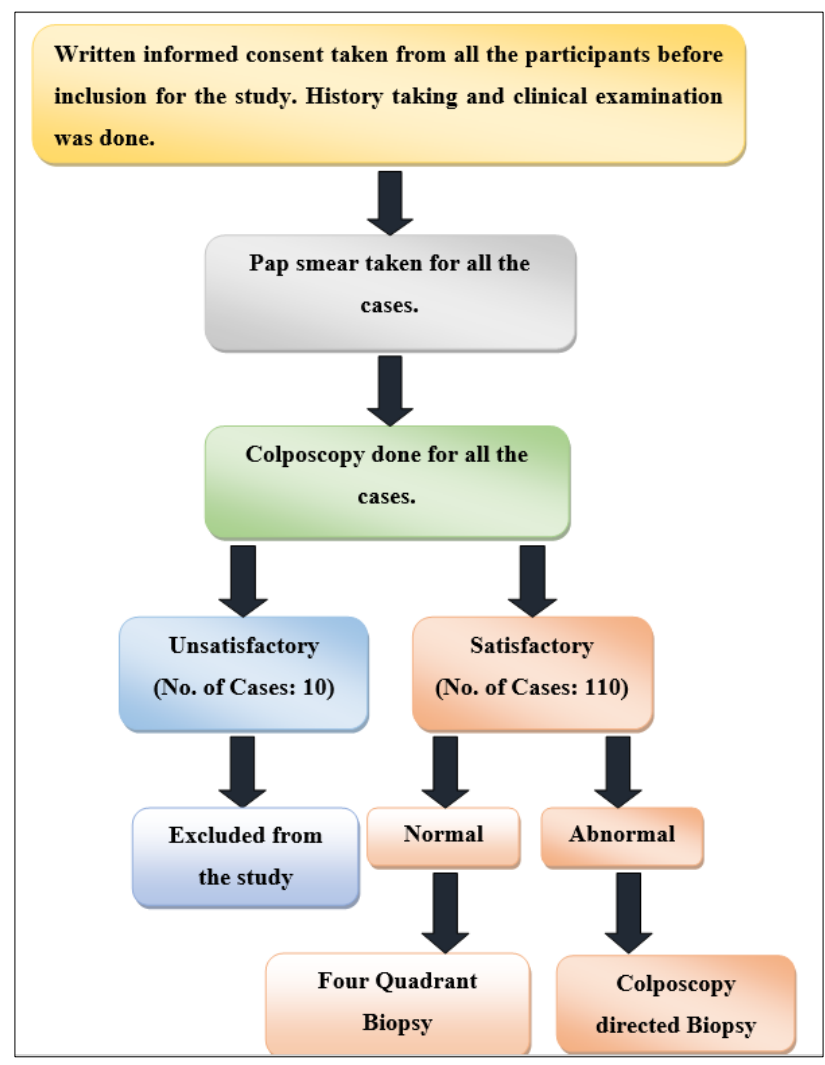

Figure 1: Sequence of events in the study conducted.

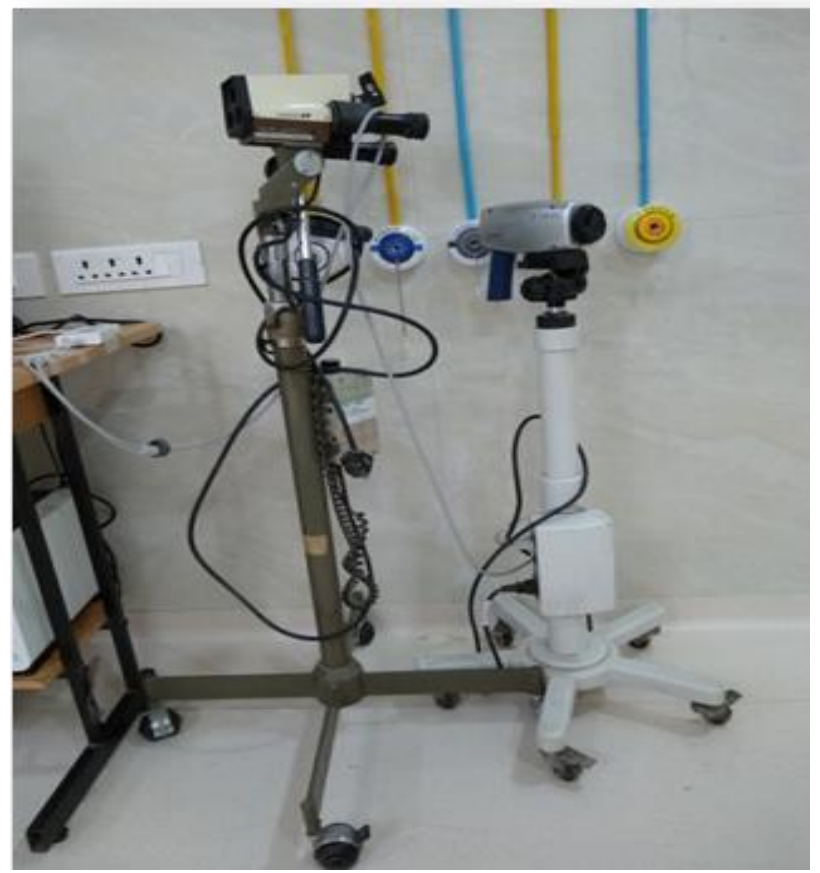

Figure 2: AC-3 model colposcope. 


\section{Colposcopic examination}

An AC-3 model colposcope (Figure 2) was used and the procedure was carried out in the minor OT of the OPD. The cervix was visualized for colour change, surface contour and any vascular abnormality. Capillaries and surface blood vessels were examined with a green filter. Colposcopy was considered unsatisfactory if the entire transformation zone was not visualized. Biopsy was taken with punch biopsy forceps under colposcopic guidance from the suspicious areas, and a four-quadrant biopsy was taken where no such area was visible. Women with unsatisfactory colposcopy (i.e. those in whom the transformation zone could not be completely visualized) were excluded from the study and were advised followup. Pap smear, colposcopy and histopathology findings were correlated and analyzed.

\section{RESULTS}

Of the 120 women, $53.33 \%$ were above 40 years of age. The women in the study were distributed according to socioeconomic status by Kuppuswamy scale of which $65 \%$ were from the lower class. It was noticed that $83.3 \%$ had education below tenth standard. Of the $83.3 \%$ women, $28.33 \%$ were illiterate.

It was seen that $70 \%$ of the women were married before the age of 20 , implying early and increased duration of exposure to sexual intercourse.

Table 1: Distribution according to the per speculum inspection findings.

\begin{tabular}{|lll|}
\hline Per speculum findings & No. of cases & $\%$ \\
\hline Atrophic & 10 & 8.33 \\
\hline Hypertrophic & 9 & 7.5 \\
\hline Erosion & 87 & 72.5 \\
\hline Suspicious & 14 & 11.66 \\
\hline Total & $\mathbf{1 2 0}$ & $\mathbf{1 0 0}$ \\
\hline
\end{tabular}

On clinical inspection of the cervix, $72.5 \%$ women had cervical erosion, $11.66 \%$ women had suspicious cervix (i.e. in the form of cervical tears, old lacerations, ectropion) while $8.33 \%$ women had atrophic cervix and $7.5 \%$ women had hypertrophied cervix (Table 1).

Table 2: Distribution of study samples according to Pap smear findings.

\begin{tabular}{|lll|}
\hline Pap smear & Frequency & $\%$ \\
\hline Normal & 52 & 43.33 \\
\hline Inflammatory & 50 & 41.67 \\
\hline LSIL & 9 & 7.5 \\
\hline HSIL & 8 & 6.67 \\
\hline Squamous cell carcinoma & 1 & 0.8 \\
\hline Total & $\mathbf{1 2 0}$ & $\mathbf{1 0 0}$ \\
\hline
\end{tabular}

All the women in the study underwent a Pap smear on their first visit. $52(43.33 \%)$ out of 120 patients were having normal Pap smear, followed by 50 (41.67\%) having inflammatory changes. $9(7.5 \%)$ were having low grade squamous intraepithelial lesions and 8 (6.67\%) having high grade squamous intraepithelial lesions and 1 (0.8) patient had squamous cell carcinoma (Table 2).

Following Pap smear, all of them had a colposcopic examination. $60(50 \%)$ women out of 120 were having normal colposcopy, followed by 39 (32.5\%) having acetowhite changes. $6(5 \%)$ were showing mosaic pattern. $10(8.33 \%)$ had unsatisfactory colposcopy i.e in these women the new SCJ could not be visualized, it was also found that these women had an atrophic cervix on clinical examination along with normal Pap smear find, thus these women were excluded from the study and advised follow-up (Table 3).

Table 3: Distribution of study samples according to colposcopy findings.

\begin{tabular}{|lll|}
\hline Colposcopy & Frequency & $\%$ \\
\hline Normal & $\mathbf{6 0}$ & $\mathbf{5 0}$ \\
\hline Abnormal & & \\
\hline Acetowhite & 39 & 32.5 \\
\hline Punctation & 03 & 2.5 \\
\hline Mosaic & 06 & 5 \\
\hline Atypical vessels & 02 & 1.66 \\
\hline Unsatisfactory & 10 & 8.33 \\
\hline Total & $\mathbf{1 2 0}$ & $\mathbf{1 0 0}$ \\
\hline
\end{tabular}

In 110 women, cervical biopsy was taken. Those with abnormal findings on colposcopy underwent a colposcopic guided biopsy while those with normal colposcopy a four-quadrant biopsy was taken. The histopathology of cervical biopsy reported $19(17.27 \%)$ were CIN I, 8 (7.27\%) were CIN II, 5 (4.54\%) were CIN III and 1 women had squamous cell carcinoma. 16 $(14.55 \%)$ out of 110 women were having normal cervical biopsy, followed by $61(55.45 \%)$ with chronic cervicitis (Table 4).

Table 4: Distribution of study samples according to cervical biopsy findings.

\begin{tabular}{|lll|}
\hline Cervical biopsy & Frequency & $\%$ \\
\hline Normal & 16 & 14.55 \\
\hline Chronic cervicitis & 61 & 55.45 \\
\hline CIN I & 19 & 17.27 \\
\hline CIN II & 08 & 7.27 \\
\hline CIN III & 05 & 4.54 \\
\hline Squamous cell carcinoma & 01 & 0.90 \\
\hline $\begin{array}{l}\text { Not taken (excluded from the } \\
\text { study) }\end{array}$ & 10 & - \\
\hline Total & $\mathbf{1 1 0}$ & $\mathbf{1 0 0}$ \\
\hline
\end{tabular}


Colposcopy was unsatisfactory in $8.33 \%$ women who were excluded from the study and advised follow-up. Histopathology was negative for intraepithelial lesion in $70 \%$ women, CIN 1 in $17.27 \%$, CIN 2 in $7.27 \%$ and CIN 3 in $4.54 \%$ women. Squamous cell carcinoma was reported in 1 woman. Pap smear and colposcopy were correlated with the gold standard histopathology. In the present study, sensitivity of Pap smear was $53.1 \%$ and specificity was $98.7 \%$. The sensitivity of colposcopy was $87.87 \%$ and specificity was $72.72 \%$. Colposcopy had higher sensitivity than pap smear but lower specificity for screening of pre-invasive cancer of cervix.

\section{Table 5: Sensitivity and specificity of Pap smear and colposcopy for screening of cancer cervix.}

\begin{tabular}{|lll|}
\hline Test & Sensitivity & Specificity \\
\hline Colposcopy & $87.87 \%$ & $72.72 \%$ \\
\hline Pap smear & $53.1 \%$ & $98.7 \%$ \\
\hline
\end{tabular}

Table 5 shows that colposcopy has higher sensitivity $(87.87 \%)$ than Pap smear $(53.1 \%)$, while specificity is higher in Pap smear (98.7\%) than colposcopy (72.72\%) for screening of cervical cancer.

\section{DISCUSSION}

Cervical cancer ranks fourth among all malignancies in women (WHO 2018). Most of these cancers stem from infection with the HPV. The worldwide HPV prevalence of cervical carcinoma is $99.7 \%$. The presence of HPV in virtually all cervical cancers implies the highest worldwide attributable fraction so far reported for a specific cause of any major human cancer.

Most early cancers are asymptomatic. Thus, diagnosis usually follows histologic evaluation of biopsies taken during colposcopic examination or from a grossly abnormal cervix. Invasive cancer of the cervix is considered to be a preventable condition as it is associated with a long pre-invasive stage making it amenable to screening and treatment. Regular screening is recommended and HPV vaccination is encouraged to lower rates of cervical cancer in the future.

Of all the slides sent for pap smear, $14.17 \%$ showed intraepithelial lesion, only 1 patient $(0.8 \%)$ was reported as squamous cell carcinoma and the rest $83 \%$ had either normal or inflammatory smear. Zainab $\mathrm{S}$ et al, in their study done in 2015 reported $21.15 \%$ normal Pap smear, $65.38 \%$ inflammatory smear, LSIL was noted in $8.65 \%$ women, HSIL in $3.84 \%$ women while malignancy on Pap smear was reported in $0.96 \%$ women. $^{6}$ Joshi et al, reported that $64 \%$ Pap smears as negative for intraepithelial lesion or malignancy (NILM). 2\% had ASCUS while $17 \%$ had LSIL and $12 \%$ women had HSIL. $2 \%$ women in the study group had squamous cell carcinoma. ${ }^{7}$ Kumari $\mathrm{P}$ et al, concluded with $46 \%$ having inflammatory smear and $5 \%$ reported with malignancy. ${ }^{8}$ A study conducted by Vidyadhar $\mathrm{S}$ et al, the following findings were reported on Pap smear, ASCUS was found in $5.8 \%$ women and ASC-H was found in $1.4 \%$ of the women. LSIL was in $6.7 \%$ of the women and HSIL in $6.2 \%$ women. NILM was found in $79.3 \%$ women which formed the majority. ${ }^{9}$

The colposcopic findings in the study showed $50 \%$ patients had no abnormality, $32.5 \%$ women showed acetowhite areas, 5\% women had mosacism, and $2.5 \%$ women had punctations while $1.66 \%$ women had atypical vessels. $8.33 \%$ women had unsatisfactory colposcopy. Colposcopy was considered unsatisfactory in those patients in whom the upper margin of the zone could not be identified. Interestingly it was found that all patients with unsatisfactory colposcopy had atrophic cervix on clinical examination. Zainab S, reported $55.76 \%$ women with squamous metaplasia on colposcopy, $22.11 \%$ women with acetowhite areas, $10.57 \%$ had fine punctations, $9.61 \%$ had coarse punctations while $2 \%$ women had mosacism. ${ }^{6}$ Joshi et al reported $27 \%$ normal colposcopy, $43 \%$ women with acetowhite areas, $16 \%$ women had punctuations while $14 \%$ women had mosacism. ${ }^{7}$ Vidhyadhar $\mathrm{S}$, et al reported $51.9 \%$ with normal colposcopy, $3.8 \%$ women had unsatisfactory colposcopy. ${ }^{9}$ Gandi SR et al, concluded with $54 \%$ having normal findings, $31 \%$ had low grade lesion, $12 \%$ had high grade or suspicious of malignancy and $3 \%$ had unsatisfactory colposcopy. ${ }^{10}$

In the present study, on biopsy $14.55 \%$ had normal report; chronic cervicitis was reported in $55.45 \%$ of the women. CIN I was present in $17.27 \%$, CIN II in $7.27 \%$ of the women and CIN III was present in $4.54 \%$ women. Squamous cell carcinoma was present in $0.90 \%$. Zainab S et al, in their study reported $69.23 \%$ women having cervicitis, CIN 1 in $23.07 \%$, CIN 2 in $5.76 \%$, CIN 3 in $0.96 \%$ and Squamous cell carcinoma in $0.96 \%$ women. $^{6}$ Joshi et al reported $48 \%$ chronic cervicitis, $28 \%$ CIN I, $11 \%$ CIN II, $4 \%$ CIN III along with $2 \%$ women having CIS, $5 \%$ women having squamous cell carcinoma and $2 \%$ women with adenocarcinoma of the cervix. ${ }^{7}$ Kumari $\mathrm{P}$ et al reported $14 \%$ women having normal smear, $47 \%$ women had cervicitis, $19 \%$ had CIN I, 5\% had CIN II, $12 \%$ had CIN III and 3\% had malignancy. ${ }^{8}$ Vidhyadhar S et al, had majority of the women having chronic cervicitis i.e. $52.9 \%$. CIN I was seen in $16.8 \%$ of the women followed by $8.2 \%$ having CIN II and $5.8 \%$ women having CIN III. Normal biopsy was reported in $16.3 \%$ women. ${ }^{9}$ Gandi SR et al on histopathology had $87 \%$ chronic cervicitis, 4\% had CIN I and II and 9\% had squamous cell carcinoma. ${ }^{10}$

The findings of Pap smear and colposcopy were correlated with the gold standard histopathology of cervical biopsy. In the present study, sensitivity of Pap smear was $53.1 \%$ with respect to cervical biopsy and specificity was $98.7 \%$. The sensitivity of colposcopy was $87.87 \%$ and specificity was $72.72 \%$. Colposcopy had higher sensitivity $(87.87 \%)$ than Pap smear $(53.1 \%)$, while specificity is higher in Pap smear (98.7\%) 
compared to colposcopy $(72.72 \%)$ for screening of preinvasive cancer of cervix. Zainab $\mathrm{S}$ et al, reported the sensitivity of Pap smear to be very low at $31.25 \%$ compared to its specificity which was $94.44 \%$. The sensitivity of colposcopy was $96.87 \%$ and specificity was $88.55 \%$. In this study too colposcopy showed a higher sensitivity and lower specificity compared to Pap smear. Low specificity was due to high incidence of acetowhite area which might be due to inflammation, immature metaplasia or latent HPV infection. ${ }^{6}$ Joshi et al reported the sensitivity of Pap smear to be $65.38 \%$ and specificity of $95.83 \%$. They concluded that Pap smear demonstrates premalignant and malignant lesions whereas colposcopy shows the exact site for biopsy for histopathological diagnosis and for further management. ${ }^{7}$ Kumari $\mathrm{P}$ et al reported the sensitivity of Pap smear to be $50 \%$ and $96.88 \%$ specificity. The sensitivity of colposcopy was $75 \%$ and the specificity was $88.54 \% .^{8}$ Vidhyadhar S et al, in their study reported the sensitivity of Pap smear to be $29.7 \%$ and specificity was $94.4 \%$. The sensitivity of colposcopy was $85.9 \%$ while its specificity was $74.3 \% .^{9}$ Gandi SR et al reported the sensitivity of Pap smear to be $69.23 \%$ and specificity of $83.9 \% \%$. The sensitivity of colposcopy was $92.3 \%$ and specificity was $60.9 \%$. Hence, colposcopy and colposcopy directed biopsy should be done along with Pap smear in screening for early detection of cervical cancer since the accuracy of detection of cervical abnormalities is higher when these two methods are used complementarily. ${ }^{10}$

\section{CONCLUSION}

Cervical cancer is one of the preventable and highly curable conditions when diagnosed in the precancerous stage. One of the major problems faced is the lack of awareness of the disease in the vast majority of the population and absence of an organized screening system in our country. The progression of preinvasive cancer cervix to invasive carcinoma cervix takes at least 10 years. Therefore, with adequate cervical cancer screening the incidence of deaths resulting from cervical cancer can be brought down. Various screening methods are available including Pap smear, colposcopy, visual inspection with acetic acid, and HPV DNA testing. In this study sensitivity and specificity of Pap smear was 53.1\% and $98.7 \%$ respectively. The sensitivity and specificity of colposcopy was $87.87 \%$ and $72.72 \%$ respectively. The results from the present study supports that combination of screening tests as a part of routine screening for cervical cancer rather than a single test can help maximize the early diagnosis in women. As it is rightly said, "prevention is better than cure". It is important to strictly implement the screening programme and spread awareness of the disease symptoms and its management to reduce the overall incidence of deaths reported due to cervical cancer.

Funding: No funding sources

Conflict of interest: None declared

Ethical approval: The study was approved by the Institutional Ethics Committee

\section{REFERENCES}

1. Sen R. Principles and management of Cancer, 2004 B.I. Publication Pvt Ltd, New Delhi; 2004:1.

2. American College of Obstetricians and Gynecologists. Cervical cancer screening and prevention. Practice Bulletin No. 157. Obstet Gynecol; 2016:127:e1-20.

3. Dinshaw KA, Shastri SS, Patil SS. Cancer control programme in India: Challenges for the new millennium. Health Administrator. 2005;17(1):10-3.

4. Monsoneg J, Bosch FX, Coursaget P, Franco E, Frazer I, Sankaranarayanan R, et al. Mini review; cervical control, priorities and new directions. Int $\mathrm{J}$ Cancer. 2004;108:329-33.

5. ACOG practice bulletin clinical management guidelines for obstetricians-gynaecologists. 2003;102(45):417-27. Monsoneg. J, Bosch. F.X, Coursaget. P, Franco. E, Frazer. I et al; Mini Review; Cervical Control, Priorities and new Directions. Int J Cancer. 2004;108:329-33.

6. Nayani ZS, Hendre PC. Comparision and correlation of pap smear with colposcopy and histopathiology in evaluation of cervix. J Evol Med Dental Sci. 2015;4:9236-9247.

7. Joshi C, Kujur P, Thakur N. Correlation of Pap smear and colposcopy in relation to histopathological findings in detection of premalignant lesions of cervix in a tertiary care centre. Int J Sci Stud. 2015;3(8):55-60.

8. Kumari P, Desai RM, Lt. Col. Dr. Dinesh U. Screening for cancer of the uterine cervix with simultaneous use of Pap smear, Colposcopy and Colposcopy guided cervical biopsy: a prospective study. J Res Obstet Gynecol Infert. 2015;1(1):9-12.

9. Vidyadhar DS, Bhattacharya DA, Bohara DS, Dwivedi DA, Agarwal DA, Gangwar DD. Comparison and correlation of cytology, colposcopy and histopathology of premalignant lesions of cervix in rural women of Barabanki District. IOSR J Dent Med Sci. 2017;16(04):13-8.

10. Gandi SR, Vishwekar PS. A study on correlation of pap smear, colposcopy and colposcopic directed biopsy in women with unhealthy cervix. J Evol Med Dent Sci. 2017;6(7):515-8

Cite this article as: Gohil AM, Ponde S, Agrawal P, $\mathrm{Bal} \mathrm{H}$. A study of evaluation of unhealthy cervix by various diagnostic modalities. Int J Reprod Contracept Obstet Gynecol 2020;9:82-6. 